\title{
GEI I-modified liposomes for non-small cell lung cancer targeting: preparation, ex vitro and in vivo evaluation
}

This article was published in the following Dove Press journal:

International Journal of Nanomedicine

12 February 2014

Number of times this article has been viewed

\author{
Liang Cheng ${ }^{1, *}$ \\ Fa-Zhen Huang ${ }^{1,2, *}$ \\ Li-Fang Cheng' \\ Ya-Qin Zhu' \\ Qing $\mathrm{Hu}^{\prime}$ \\ Ling $\mathrm{Li}^{\prime}$ \\ Lin Wei' \\ Da-Wei Chen'
}

'Department of Pharmaceutics, College of Pharmaceutical Science, Soochow University, Suzhou, Jiangsu Province, ${ }^{2}$ Department of Pharmacy, Central Hospital of Zaozhuang Minging Group, Zaozhuang, Shandong Province, People's Republic of China

*These authors contributed equally to this work
Correspondence: Da-Wei Chen College of Pharmaceutical Science, Soochow University, 199 Ren'ai Road, Suzhou 215123, People's Republic of China Tel +8651265884729

Fax +86 2423986250

Email chendawei@syphu.edu.cn
Abstract: Non-small cell lung cancer (NSCLC) is a serious threat to human health, and $40 \%-80 \%$ of NSCLCs express high levels of epidermal growth factor receptor (EGFR). GE11 is a novel peptide and exhibits high affinity for EGFR binding. The aim of this study was to construct and evaluate GE11-modified liposomes for targeted drug delivery to EGFR-positive NSCLC. Doxorubicin, a broad-spectrum antitumor agent, was chosen as the payload. GE11 was conjugated to the distal end of DSPE-PEG ${ }_{2000}-\mathrm{Mal}_{\text {by }}$ an addition reaction with a conjugation efficiency above 90\%. Doxorubicin-loaded liposomes containing GE11 (GE11-LP/DOX) at densities ranging from $0 \%$ to $15 \%$ were prepared by combination of a thin film hydration method and a post insertion method. Irrespective of GE11 density, the physicochemical properties of these targeted liposomes, including particle size, zeta potential, and drug entrapment efficiency, were nearly identical. Interestingly, the cytotoxic effect of the liposomes on A549 tumor cells was closely related to GE11 density, and liposomes with 10\% GE11 had the highest tumor cell killing activity and a 2.6-fold lower half maximal inhibitory concentration than that of the nontargeted counterpart (PEG-LP/DOX). Fluorescence microscopy and flow cytometry analysis revealed that GE11 significantly increased cellular uptake of the liposomes, which could be ascribed to specific EGFR-mediated endocytosis. It was found that multiple endocytic pathways were involved in entry of GE11-LP/DOX into cells, but GE11 assisted in cellular internalization mainly via the clathrin-mediated endocytosis pathway. Importantly, the GE11-modified liposomes showed enhanced accumulation and prolonged retention in tumor tissue, as evidenced by a 2.2-fold stronger mean fluorescence intensity in tumor tissue than the unmodified liposomes at 24 hours. In summary, GE11-modified liposomes may be a promising platform for targeted delivery of chemotherapeutic drugs in NSCLC.

Keywords: epidermal growth factor receptor, nanosized carrier, targeted drug delivery, cellular uptake mechanism, in vivo imaging

\section{Introduction}

Lung cancer is one of the most dangerous diseases in humans, accounts for nearly $15 \%$ of all new cancers, and causes more than one million deaths annually. ${ }^{1,2}$ It is estimated that approximately $85 \%-90 \%$ of lung cancer patients have a histologic diagnosis of non-small cell lung cancer (NSCLC). ${ }^{3}$ Currently, chemotherapy remains the primary treatment strategy for patients with NSCLC. Unfortunately, the treatment effect is usually unsatisfactory due to serious systemic toxicity and limited killing of tumor cells. ${ }^{4}$ Therefore, being able to exploit a novel drug delivery strategy to improve drug efficacy for NSCLC is of great importance.

Nanoparticles in the size range of 20-200 $\mathrm{nm}$ can be easily leaked into the tumor region and be retained there for a long time, owing to the well known enhanced 
permeability and retention effect. ${ }^{5-7}$ By virtue of this characteristic, chemotherapeutic drugs can be selectively delivered to tumor tissue by physical encapsulation and/or chemical attachment to diverse nanocarriers, ${ }^{8,9}$ achieving so-called passive tumor targeting. Compared with other nanosized drug delivery carriers, liposomes have unique advantages, ${ }^{10-12}$ including: the lipids used to prepare liposomes being nontoxic and able to be utilized by the body; pharmaceutical grade lipids being commercially available; and the preparation processes for liposomal formulations being convenient, with large-scale manufacture being easy to achieve. At present, a second-generation doxorubicin-loaded liposomal product $\left(\right.$ Doxil $^{\circledR}$ ) has been approved by the US Food and Drug Administration and has been shown to be effective in the clinic.

It is worthy of note that the surfaces of most cancer cells commonly overexpress certain specific receptors. ${ }^{13-15}$ Consequently, conjugation of targeting ligands on the periphery of nanocarriers that specifically bind to these receptors can enable nanocarriers to recognize tumor cells after reaching the tumor region, enhance cellular uptake of the nanocarriers, and efficiently deliver their cargo into cancer cells. Application of targeting ligand-modified nanocarriers to achieve targeted delivery of antitumor drugs is becoming an important strategy in the treatment of cancer. Overexpression of epidermal growth factor receptor (EGFR) has been found in a wide variety of malignant cells, ${ }^{16,17}$ with about $40 \%-80 \%$ of NSCLCs showing high EGFR expression. GE11 is a novel peptide first reported on by Li et al in 2005, ${ }^{18}$ and its high affinity for certain EGFR-positive tumor cells has been verified ex vitro and in vivo. ${ }^{19,20}$ However, the potential for use of this peptide as a targeting ligand to achieve targeted drug delivery to tumors, especially NSCLC, has not as yet been reported.

Enlightened by previous work, we hypothesized that a GE11-modified nanocarrier may be a promising candidate for targeted delivery of antitumor drugs to NSCLC overexpressing EGFR. In this study, liposomes were selected as the drug delivery nanocarrier because of their abovementioned merits, and GE11-modified liposomes were prepared by the widely used thin film hydration and post insertion methods. ${ }^{21-23} \mathrm{~A}$ human lung adenocarcinoma (A549) cell line, which has been demonstrated to overexpress EGFR, was used as the tumor model of NSCLC. ${ }^{24-26}$ Doxorubicin, which is sensitive to A549 cells, was selected as the payload because doxorubicin can be easily loaded into liposomes with high entrapment efficiency by the $\mathrm{pH}$ gradient method. ${ }^{27}$

It is generally accepted that the density of the targeting ligands on the surface of a nanocarrier plays a vital role in determining the efficiency of drug delivery. ${ }^{28,29}$ Assuming that GE11 can specifically bind to EGFR on NSCLC cells and increase the cellular uptake of liposomes, the optimal GE11 density required to achieve the best targeting efficiency needs to be determined. Further, to our knowledge, cellular uptake of ligand-modified nanocarriers is primarily mediated by clathrin-dependent and clathrin-independent pathways. ${ }^{30,31}$ However, with respect to this GE11-modified liposome, much less is presently known about the uptake mechanism. Therefore, we needed to clarify the cellular uptake mechanism for this targeted liposome to help us understand better the role of GE11 in facilitating cellular internalization of the liposome.

In the present study, we prepared a series of doxorubicinloaded liposomes with different GE11 densities ( $0 \%-15 \%)$ and investigated their characteristics, including size distribution, zeta potential, drug entrapment efficiency, and morphology. The optimal GE11 density was determined by cytotoxicity experiments. Cellular uptake of the liposomes was assessed by fluorescence microscopy and flow cytometry. The mechanism of cellular uptake of the liposomes was systematically investigated as well. Finally, an A549 tumor model was constructed and the tumor-targeting potential of the liposome in vivo was examined using a near-infrared fluorescence imaging system.

\section{Materials and methods Materials}

Doxorubicin hydrochloride was obtained from HuaFeng United Technology Co, Ltd (Beijing, People's Republic of China), cholesterol from Sinopharm Chemical Reagent Co, Ltd (Shanghai, People's Republic of China), and soy phosphatidylcholine from Tywei Pharmaceutical Co, Ltd, (Shanghai, People's Republic of China). 1,2-distearoyl-snglycero-3-phosphoethanolamine-N-[maleimide (polyethylene glycol) 2000)] (DSPE-PEG 2000 -Mal) and 1,2-distearoyl-snglycero-3-phosphoethanolamine- $\mathrm{N}-[$ methoxy (polyethylene glycol) 2000] (DSPE-PEG ${ }_{2000}$ ) was purchased from Avanti Polar Lipids (Alabaster, AL, USA). GE11 peptide with terminal cysteine (Cys-YHWYGYTPQNVI) was synthesized by GL Biochem Ltd (Shanghai, People's Republic of China). Roswell Park Memorial Institute-1640 medium, penicillin, streptomycin, fetal bovine serum, and trypsin solution were sourced from Gibco BRL (Gaithersberg, MD, USA). 3-(4,5Dimethyl-thiazol-2-yl)-2,5-diphenyl-tetrazolium bromide (MTT), Hoechst 33342, and Lyso tracker green DND-26 were purchased from Molecular Probes (Eugene, OR, USA). Chlorpromazine hydrochloride and colchicine were obtained from Shanghai Genestar Co, Ltd (Shanghai, People's Republic 
of China). Filipin was from Cayman Chemical Company (Ann Arbor, MI, USA) and Cy7 mono NHS ester was from Mycomebio Biomedical Science and Technology Center (Beijing, People's Republic of China). All other chemicals were of analytical or chromatographic grade.

\section{Cell lines and animal model}

An A549 NSCLC cell line and a K562 human leukemia cell line were obtained from the Shanghai Institute of Cell Biology. Cells were cultured in Roswell Park Memorial Institute-1640 medium supplemented with $10 \%(\mathrm{v} / \mathrm{v})$ fetal bovine serum, $100 \mathrm{IU} / \mathrm{mL}$ penicillin, and $100 \mu \mathrm{g} / \mathrm{mL}$ streptomycin sulfate at $37^{\circ} \mathrm{C}$ in $5 \% \mathrm{CO}_{2}$.

Male Balb/c nude mice aged 4-6 weeks were purchased from Shanghai Laboratory Animal Co, Ltd (Shanghai, People's Republic of China). The mice were housed at $25^{\circ} \mathrm{C}$ and $55 \%$ humidity under natural light/dark conditions and allowed free access to food and water. All animal procedures were performed following the protocol approved by the animal study committee of Soochow University.

\section{Synthesis of DSPE-PEG ${ }_{2000}-$ GEI I}

Synthesis of DSPE-PEG 2000 -GE11 was performed according to a previous study with some modifications. ${ }^{32}$ First, DSPE-PEG $_{2000}$-Mal $(20.0 \mathrm{mg}, 0.0075 \mathrm{mmol})$ was dissolved in $5 \mathrm{~mL}$ of deionized water, followed by addition of GE11 $(18.6 \mathrm{mg}, 0.011 \mathrm{mmol})$. The reaction was maintained for 24 hours at room temperature under gentle stirring and the reaction process was monitored by thin-layer chromatography $\left(\mathrm{CHCl}_{3}: \mathrm{CH}_{3} \mathrm{OH}=4: 1\right)$. When the spot of DSPE-PEG ${ }_{2000}$ Mal disappeared, the reaction ceased and the conjugation efficiency was determined by a gradient high-pressure liquid chromatography (HPLC) method. After dialysis and lyophilization, the DSPE-PEG ${ }_{2000}-\mathrm{GE} 11$ obtained was analyzed by ${ }^{1} \mathrm{H}-\mathrm{NMR}(400 \mathrm{mHz}$, Varian Medical Systems, Palo Alto, CA, USA) in dimethyl sulfoxide and Fourier transform infrared spectra (ProStar LC240, Varian Medical Systems).

The detailed HPLC conditions were as follows: chromatographic separation was performed on a Promosil C18 column $(250 \mathrm{~mm} \times 4.6 \mathrm{~mm}, 5 \mu \mathrm{m})$ with the column temperature set at $30^{\circ} \mathrm{C}$. The mobile phase consisted of $100 \%$ acetonitrile- $0.1 \%$ trifluoroacetic acid (eluent A) and 100\% water- $0.1 \%$ trifluoroacetic acid (eluent B), and the eluted gradient was set from $28 \%$ eluent $\mathrm{A} / 72 \%$ eluent $\mathrm{B}$ to $53 \%$ eluent $\mathrm{A} / 47 \%$ eluent $\mathrm{B}$ in 25 minutes. The eluting flow rate was fixed at $1.0 \mathrm{~mL}$ per minute. The monitor wavelength was $220 \mathrm{~nm}$ and the injection volume was $20 \mu \mathrm{L}$.

\section{Preparation of GEI I-modified liposomes}

GE11-modified liposomes loaded with doxorubicin (GE11LP/DOX) were prepared using a combination of the thin film hydration method and post insertion method. Briefly, lipids of soy phosphatidylcholine and cholesterol at a molar ratio of 2:1 were dissolved in ethanol, and the ethanol was then removed by rotary evaporation. The lipid film obtained was hydrated in citrate buffer ( $\mathrm{pH} 4.0$ ) for 20 minutes at $40^{\circ} \mathrm{C}$. Subsequently, the solution was sonicated at $100 \mathrm{~W}$ on ice for 10 minutes and treated further with high pressure at 15,000 psi for 5 minutes using a microfluidization device (Nano DeBEE, South Easton, MA, USA). The blank liposomal solution (125 mg, $0.2 \mathrm{mmol}$ ) was diluted using $0.2 \mathrm{M}$ disodium hydrogen phosphate to $\mathrm{pH} 7.4$, and doxorubicin solution $(8.3 \mathrm{mg}, 0.014 \mathrm{mmol})$ was added and incubated for 30 minutes at $70^{\circ} \mathrm{C}$. Finally, DSPE$\mathrm{PEG}_{2000}-\mathrm{GE} 11$ and DSPE-PEG 2000 at different molar ratios were added to the doxorubicin-loaded liposomal solution and incubated at $55^{\circ} \mathrm{C}$ for 60 minutes to enable insertion. The unloaded doxorubicin was removed by dialysis against water. As a control, liposomes without GE11 (PEG-LP/DOX) was prepared using the same method.

\section{Characterization of liposomes}

Particle size and zeta potential

The particle size and zeta potential of the plain liposomes, LP/DOX, PEG-LP/DOX, and GE11-LP/DOX were measured by dynamic light scattering (NicompTM380ZLS zeta potential/particle sizer, Particle Sizing Systems, Port Richey, FL, USA). Before analysis, each sample was diluted 20-fold in distilled water ( $\mathrm{pH}$ 7.4) to obtain the appropriate liposomal concentration.

\section{Morphology}

The morphology of the liposomes was observed using a transmission electron microscope (TecnaiG220, FEI, Hillsboro, OR, USA). The liposomal solution was dropped onto a carbon-coated copper grid followed by drying in air, and the sample was then subjected to observation.

\section{Encapsulation efficiency}

The encapsulation efficiency of doxorubicin in the liposomes was determined by HPLC. Briefly, $0.5 \mathrm{~mL}$ of the liposomal sample was first added in Super filter (UFC501096, Millipore Corporation, Billerica, MA, USA) and then centrifuged at $10,000 \mathrm{rpm}$ for 30 minutes. The amount of ultrafiltrated doxorubicin was measured by HPLC. The encapsulation efficiency of doxorubicin was calculated using the formula: $\left(M_{1}-M_{2}\right) / M_{1} \times 100 \%$, where $M_{1}$ and $M_{2}$ are defined as the 
mass of the initially added doxorubicin and nonnencapsulated doxorubicin, respectively.

Chromatographic separation was performed on a Promosil C18 column $(250 \mathrm{~mm} \times 4.6 \mathrm{~mm}, 5 \mu \mathrm{m})$ with the column temperature set at $30^{\circ} \mathrm{C}$. The mobile phase was composed of $65 \%(\mathrm{v} / \mathrm{v})$ methanol in ammonium dihydrogen phosphate buffer ( $\mathrm{pH}$ 2.8). The eluting flow rate was fixed at $1.0 \mathrm{~mL}$ per minute. The monitor wavelength was set at $491 \mathrm{~nm}$ and the injection volume was $20 \mu \mathrm{L}$.

\section{Cytotoxicity test}

The cytotoxicity of liposomes with GE11 densities ranging from $2.5 \%$ to $15 \%$ was evaluated by MTT assay. A549 cells were seeded in 96-well plates at a density of $8 \times 10^{3}$ cells per well and cultured for 24 hours. Next, the culture medium was withdrawn and replaced by medium containing GE11-LP/DOX solution (doxorubicin concentration $7.5 \mu \mathrm{g} / \mathrm{mL})$. After 48 hours, $100 \mu \mathrm{L}$ of MTT $(0.5 \mathrm{mg} / \mathrm{mL})$ were added to each well and incubated for 4 hours. Finally, $100 \mu \mathrm{L}$ of dimethyl sulfoxide was added to each well, and the absorbance of each well was measured using a microplate reader (Thermo Scientific, Waltham, MA, USA) at $492 \mathrm{~nm}$. Cell viability was calculated by determining the viability of treated cells relative to that of the nontreated controls. To exclude the cytotoxic effect of the liposomal carrier and GE11 on A549 cells, the cytotoxicity of liposomes without doxorubicin, including plain liposomes, PEG-LP, and GE11-LP, was evaluated by MTT assay before screening for the optimal GE11 density. Half maximal inhibitory concentrations $\left(\mathrm{IC}_{50}\right)$ for free doxorubicin, PEG-LP/DOX, and GE11-LP/DOX with the optimal GE11 density were determined using the same method. The values were calculated from a best fit line of at least three points in the linear range of cell viability.

\section{Cellular uptake study Observation of cellular uptake by confocal microscopy}

First, $1 \times 10^{4}$ A549 cells were seeded in 24-well plates and cultured for 24 hours. PEG-LP/DOX or GE11-LP/ DOX solution $(4 \mu \mathrm{g} / \mathrm{mL}$ doxorubicin diluted in serum-free medium) was incubated with cells for 1 hour or 2 hours. After removal of the medium, the cells were treated with Hoechst $33342(10 \mu \mathrm{g} / \mathrm{mL})$ for 20 minutes. Finally, the cells were rinsed three times with phosphate-buffered saline ( $\mathrm{pH} 7.4$ ) and observed at 40× magnification using a confocal microscope (TCS-SP2, Leica, Heidelberg, Germany) with $488 \mathrm{~nm} / 560 \mathrm{~nm}$ for doxorubicin and
$350 \mathrm{~nm} / 461 \mathrm{~nm}$ for Hoechst 33342. To observe whether or not free GE11 could hinder cellular uptake of GE11-LP/ DOX, A549 cells were preincubated with free GE11 (20 $\mu \mathrm{g} / \mathrm{mL}$ ) for 30 minutes before they were exposed to the GE11-LP/DOX solution.

\section{Flow cytometry analysis}

Quantitative analysis of cellular uptake of doxorubicin by A549 cells and K562 cells was done by flow cytometry. The cells were seeded at a density of $1 \times 10^{5}$ cells per well in sixwell plates and cultured for 24 hours at $37^{\circ} \mathrm{C}$. The medium was replaced with PEG-LP/DOX or GE11-LP/DOX solution at a final concentration of $4 \mu \mathrm{g} / \mathrm{mL}$ doxorubicin for one hour or two hours at $37^{\circ} \mathrm{C}$. The cells were then trypsinized, washed three times with cold phosphate-buffered saline, centrifuged at 1,500 rpm for 3 minutes, and resuspended in $0.5 \mathrm{~mL}$ of phosphate-buffered saline. The resulting cell suspension was analyzed by flow cytometry (FC500, Beckman Coulter, Brea, CA, USA) equipped with an argon ion laser $(488 \mathrm{~nm})$ as the excitation source. The fluorescence of doxorubicin was detected at $560 \mathrm{~nm}$ (FL2-H). Data for the individual fluorescence of $1 \times 10^{4}$ cells were collected for each sample. Cells incubated with medium were used as the negative control. For the competition experiments, free GE11 $(20 \mu \mathrm{g} / \mathrm{mL})$ was preincubated with A549 cells for 30 minutes, followed by continued incubation with GE11-LP/DOX solution.

\section{Study of cellular uptake mechanism Low temperature and ATP depletion experiments}

To evaluate the effect of low temperature on cellular uptake, A549 cells were preincubated at $4^{\circ} \mathrm{C}$ for 30 minutes. After addition of PEG-LP/DOX or GE11-LP/DOX solution ( $4 \mu \mathrm{g} / \mathrm{mL}$ doxorubicin) and culture at the same temperature for a further hour, the cells were trypsinized and centrifuged at 1,500 rpm for 3 minutes to obtain a cell pellet, which were subsequently resuspended in phosphate-buffered saline and examined by flow cytometry. To evaluate the effect of ATP depletion, A549 cells were preincubated with sodium azide $10 \mathrm{mM}$ and 2-deoxy-d-glucose $6.5 \mathrm{mM}$ in phosphate-buffered saline $\left(\mathrm{pH} \mathrm{7.4)}\right.$ at $37^{\circ} \mathrm{C}$ for one hour. Next, the cells were treated with PEG-LP/DOX or GE11$\mathrm{LP} / \mathrm{DOX}$ solution ( $4 \mu \mathrm{g} / \mathrm{mL}$ doxorubicin) in the presence of sodium azide and 2-deoxy-d-glucose at $37^{\circ} \mathrm{C}$ for a further hour. Finally, the cells were trypsinized and collected for analysis by flow cytometry. Cellular uptake at $37^{\circ} \mathrm{C}$ was used as a control and its fluorescence intensity was expressed as $100 \%$. 


\section{Cellular uptake experiments with various endocytosis inhibitors}

To study the effect of endocytosis inhibitors on cellular uptake of PEG-LP/DOX and GE11-LP/DOX, A549 cells were preincubated individually with the following inhibitors: chlorpromazine $(10 \mu \mathrm{g} / \mathrm{mL})$, colchicine $(40 \mu \mathrm{g} / \mathrm{mL})$, and filipin $(4 \mu \mathrm{g} / \mathrm{mL})$. After preincubation for one hour, fresh medium containing PEG-LP/DOX or GE11-LP/DOX solution $(4 \mu \mathrm{g} / \mathrm{mL}$ doxorubicin) with inhibitors at the abovementioned concentrations was added and further incubated for one hour. Subsequently, the cells were washed three times with cold phosphate-buffered saline ( $\mathrm{pH}$ 7.4). To measure the inhibitory effect quantitatively, the cells were trypsinized and harvested for flow cytometry analysis. Cells in the presence of PEG-LP/DOX or GE11-LP/DOX but without inhibitor treatment were used as controls and their fluorescence intensities were expressed as $100 \%$. Prior to the inhibition experiment, the toxicity of each endocytosis inhibitor at a defined concentration was assessed by MTT assay.

\section{Observation by confocal laser scanning microscopy}

Confocal laser scanning microscopy was used to investigate the intracellular distribution of the liposomes. A549 cells were seeded on glass coverslips, which were placed in six-well plates and cultured at $37^{\circ} \mathrm{C}$. After 24 hours, PEG-LP/DOX or GE11-LP/DOX solution with $4 \mu \mathrm{g} / \mathrm{mL}$ doxorubicin was added and incubated for 1 hour or 2 hours at $37^{\circ} \mathrm{C}$. The medium was then removed and the cells were treated with Lyso tracker green $(80 \mu \mathrm{g} / \mathrm{mL})$ for 60 minutes and Hoechst $33342(10$ $\mu \mathrm{g} / \mathrm{mL}$ ) for 20 minutes. Finally, the cells were treated with $5 \%$ paraformaldehyde at room temperature for 15 minutes to fix the cells and imaged by confocal laser scanning microscopy (TCS-SP2, Leica). The excitation and emission wavelengths of Lyso tracker green were $504 \mathrm{~nm}$ and $534 \mathrm{~nm}$, respectively.

\section{In vivo imaging study}

The EGFR-overexpressing tumor xenograft model was established by inoculation of $1 \times 10^{7}$ cells (in $100 \mu \mathrm{L}$ of serumfree medium) into the subcutaneous tissue of the right hind leg in live nude mice. When the size of the tumors reached $0.4-0.6 \mathrm{~cm}$ in diameter, $200 \mu \mathrm{L}$ of Cy7-labeled PEG-LP or Cy7-labeled GE11- PEG-LP (20 $\mu \mathrm{g} / \mathrm{mL}$ Cy7) was injected into the tumor-bearing mice via the tail vein. After the mice were anesthetized, whole body fluorescence images were acquired using the Cy7 channel (excited at $747 \mathrm{~nm}$ and recorded at $774 \mathrm{~nm})$ at different time points $(2,8,12$, 24 , and 36 hours). At the same time, the mean fluorescence intensity of Cy7-labeled liposomes in the tumor region was calculated using a near-infrared fluorescence imaging system (Kodak, Rochester, New York, NY, USA). Liposome labeled with the near infrared dye, Cy7, was prepared by a two-step process: first, the amine group of DSPE was reacted with the succinimidyl ester of $\mathrm{Cy} 7$, and DSPE-Cy 7 was then incorporated into the liposome according to the methods mentioned earlier and the content of DSPE-Cy7 was fixed at $0.5 \mathrm{~mol} \%$ of total lipid content.

\section{Statistical analysis}

The data were expressed as the mean \pm standard deviation. The resulting values from each experiment were compared by one-way analysis of variance, and multiple comparisons between the groups were performed using the StudentNewman-Keuls method. Statistical significance was set at a level of $P<0.05$.

\section{Results and discussion Synthesis and characterization of DSPE-PEG ${ }_{2000}-$ GEI I}

GE11 was conjugated to DSPE-PEG ${ }_{2000}$-Mal by an addition reaction and the structure of the product was verified by ${ }^{1} \mathrm{H}-\mathrm{NMR}$ and Fourier transform infrared spectroscopy. As shown in Figure 1A, the peaks at $0.81 \mathrm{ppm}$ and $1.23 \mathrm{ppm}$ were attributed to methyl and methylene protons in DSPE, while the peaks at $3.53 \mathrm{ppm}$ and $6.5-9.3 \mathrm{ppm}$ were attributed to PEG and GE11, respectively. In the Fourier transform infrared spectrum (Figure 1B), the peak at $1,105 \mathrm{~cm}^{-1}$ was the stretching vibration of $\mathrm{C}-\mathrm{O}-\mathrm{C}$ in the $\mathrm{PEG}$ segment and the peak at $1,679 \mathrm{~cm}^{-1}$ was the stretching vibration of $\mathrm{C}(=\mathrm{O})-\mathrm{N}$ in GE11. These results suggested that GE11 was successfully conjugated to DSPE-PEG ${ }_{2000}-$ Mal.

Further, the conjugation efficiency of GE11 to DSPE$\mathrm{PEG}_{2000}$-Mal was quantitatively determined by HPLC. From the chromatogram of the reaction solution (Figure 1C-d), it was interesting to see that there was an additional peak at $11.2 \mathrm{~min}$ utes over and above the characteristic peaks of the solvents and GE11. We speculated that the new peak could be ascribed to the dimer of GE11 due to the residual thiol group in GE11 molecule. To confirm this, DL-dithiothreitol (DTT), a reducing agent, was added to the reaction solution before HPLC determination. As shown in Figure 1C-e, the peak at 11.2 minutes disappeared while the peak intensity corresponding to GE11 increased after treatment with DTT. This result validated our assumption well and indicated a need for treatment with DTT before analysis by HPLC. The calculated conjugated efficiency of GE11 was above $90 \%$, indicating that most GE11 molecules were reacted with DSPE-PEG ${ }_{2000}-$ Mal. 

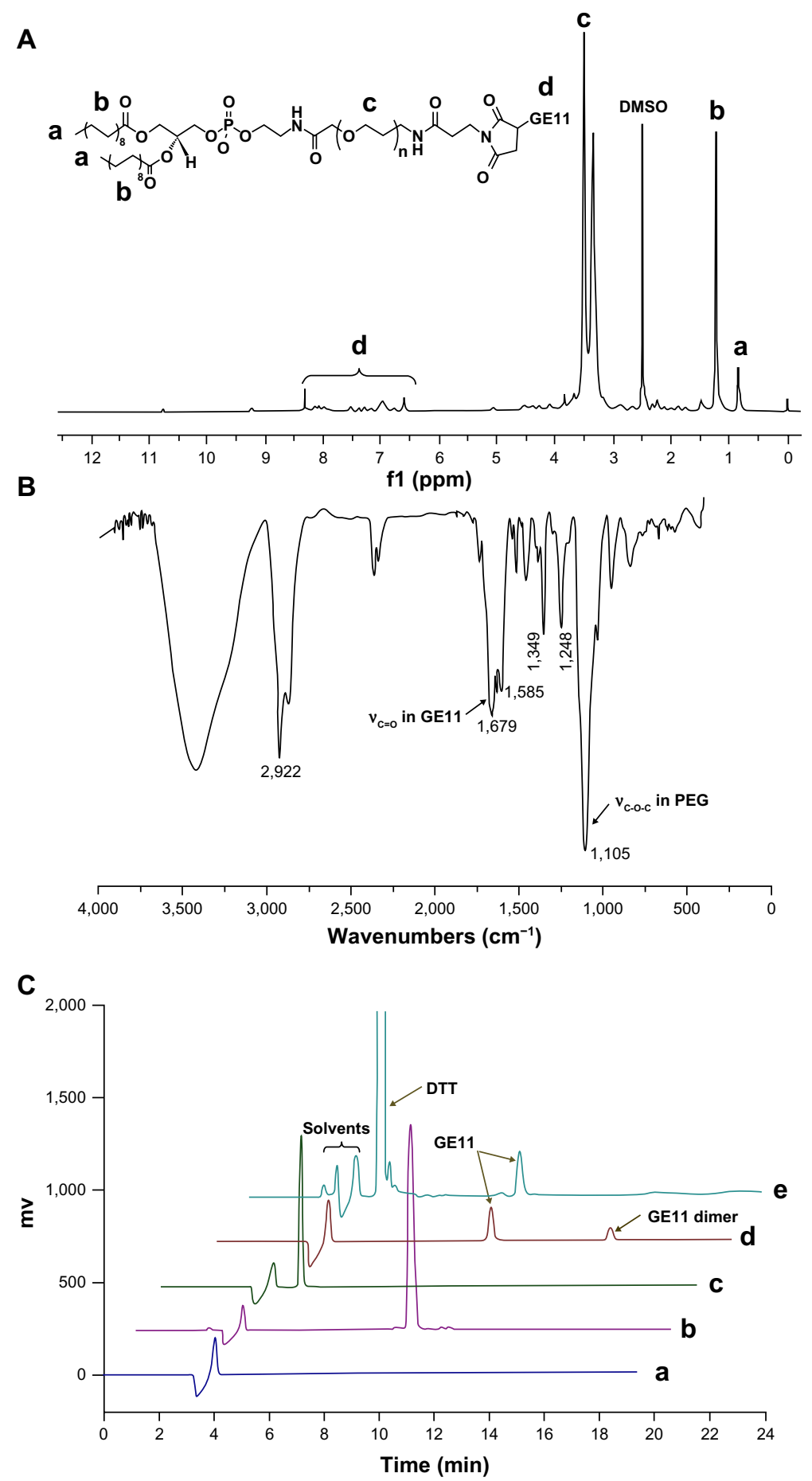

Figure I 'H-NMR (A) and Fourier transform infrared spectra (B) for DSPE-PEG ${ }_{2000}{ }^{-G E I I ~ a n d ~ h i g h-p r e s s u r e ~ l i q u i d ~ c h r o m a t o g r a p h i c ~ c u r v e s ~ f o r ~ D S P E-P E G ~} 2000-$ Mal (C-a), free GEII (C-b), DTT (C-c), the reaction mixture (C-d), and the reaction mixture treated with DTT (C-e).

Abbreviations: DSPE, I,2-distearoyl-sn-glycero-3-phosphoethanolamine; PEG, polyethylene glycol; DTT, DL-dithiothreitol; DMSO, dimethyl sulfoxide.

\section{Preparation and characterization} of GEI I-LP/DOX

The preparation procedures used for GE11-LP/DOX were divided into two steps (as shown in Figure 2A). First, doxorubicin-loaded liposomes without PEGylation were prepared using the thin film hydration and $\mathrm{pH}$ gradient methods.
Later, solutions containing different molar ratios of DSPE$\mathrm{PEG}_{2000}$ to DSPE-PEG ${ }_{2000}$-GE11 (shown in Table 1) were mixed with the doxorubicin-loaded liposomes and incubated at $55^{\circ} \mathrm{C}$ for one hour, yielding GE11-LP/DOX at GE11 densities ranging from $0 \%$ to $15 \%$. The physicochemical characteristics of these liposomes are shown in Table 1. It can 
A

B

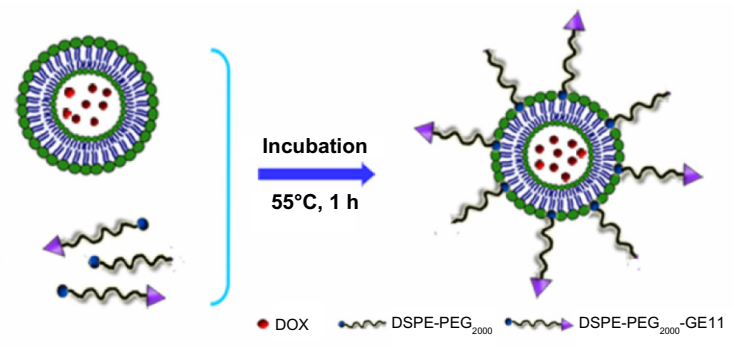

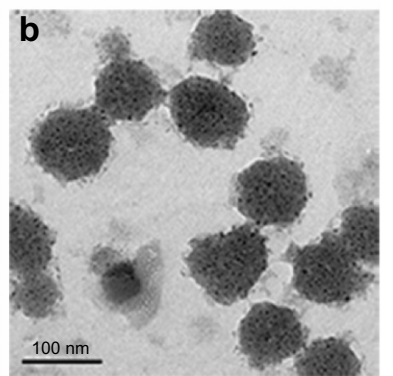

Figure 2 Schematic illustration of the post insertion method used to prepare doxorubicin-loaded liposomes containing GEII (A) and transmission electron micrographs of doxorubicin-loaded liposomes (B-a) and doxorubicin-loaded liposomes containing GEII (B-b).

Abbreviations: DOX, doxorubicin; PEG, polyethylene glycol; DSPE, I,2-distearoylsn-glycero-3-phosphoethanolamine.

be seen that the particle size and zeta potential of the plain liposomes and LP/DOX were nearly identical, indicating that encapsulation of doxorubicin into the liposome did not affect the physicochemical characteristics of the liposome. Moreover, it should be noted that the mean particle size, zeta potential, and encapsulation efficiency of GE11-LP/ DOX were nearly the same irrespective of the GE11 density, suggesting that modification by GE11 had little influence on the characteristics of the liposomes. Interestingly, the mean particle size of GE11-LP/DOX was about $7 \mathrm{~nm}$ larger than that of LP/DOX, this slight difference suggesting that DSPE$\mathrm{PEG}_{2000}$-GE11 was successfully inserted into LP/DOX. Transmission electron microscopic images of LP/DOX and

GE11-LP/DOX showed that the morphology of LP/DOX was regularly spherical (Figure $2 \mathrm{~B}-\mathrm{a}$ ), while a rough surface was observed for GE11-LP/DOX (Figure 2B-b), which was probably due to dehydration and shrinkage of the hydrophilic PEG chains.

\section{Screening of optimal GEI I density and $\mathrm{IC}_{50}$ test}

Generally, the targeting ligand density on the surface of nanocarriers is closely related to targeting efficiency. In this study, to optimize the GE11-LP/DOX ligand density, an MTT assay was performed using A549 cells. With the aim of excluding the cytotoxic effect of the liposomal carrier and GE11 on A549 cells, the cytotoxicity of liposomes without doxorubicin was evaluated first. As shown in Figure 3A, all experimental groups tested showed high cell viability (above 95\%), indicating that the liposomal carrier and GE11 were nontoxic to A549 cells. It was later found that the cytotoxicity of GE11-LP/DOX was highly dependent on the density of GE11 (see Figure 3B). GE11-LP/DOX showed stronger cytotoxicity compared with PEG-LP/DOX $(P<0.05)$ only at a GE11 density of $2.5 \%$. As the GE11 density steadily increased, the cell viability gradually decreased, reaching a minimum value of about $25 \%$ when GE11 density was $10 \%$. Interestingly, the cell viability for liposomes with a $15 \%$ GE11 density (about 26\%) was very similar to that for liposomes with a $10 \%$ GE11 density, indicating that a GE11 density of $10 \%$ was enough to enable receptorligand binding. Taken together, these results demonstrated that introduction of GE11 was beneficial for improving the cytotoxic effect of the liposomes and that the GE11 density had a critical impact on the antitumor activity of the liposomes. In this study, GE11-LP/DOX with a GE11 density of $10 \%$ showed the best antitumor effect, so this

Table I Physicochemical characteristics of liposomes loaded with doxorubicin $(n=3)$

\begin{tabular}{|c|c|c|c|c|c|c|}
\hline \multirow[t]{2}{*}{ Formulations } & \multicolumn{2}{|c|}{$\begin{array}{l}\text { Molar ratios of PEG components to } \\
\text { phospholipid }\end{array}$} & \multirow[t]{2}{*}{$\begin{array}{l}\text { Particle } \\
\text { size }(\mathrm{nm})\end{array}$} & \multirow[t]{2}{*}{ PDI } & \multirow[t]{2}{*}{$\begin{array}{l}\text { Zeta potential } \\
(\mathrm{mV})\end{array}$} & \multirow[t]{2}{*}{$\begin{array}{l}\text { EE } \\
(\%)\end{array}$} \\
\hline & DSPE-PEG $_{2000}$ & DSPE-PEG $_{2000}$-GEII & & & & \\
\hline LP & 0 & 0 & $112.5 \pm 0.4$ & 0.187 & $-13.7 \pm 0.7$ & 0 \\
\hline LP/DOX & 0 & 0 & $116.7 \pm 1.0$ & 0.178 & $-14.7 \pm 0.5$ & $93.1 \pm 1.2$ \\
\hline PEG-LP/DOX & 15 & 0 & $123.7 \pm 1.2$ & 0.167 & $-8.0 \pm 0.7$ & $92.8 \pm 0.5$ \\
\hline 2.5\% GEII-LP/DOX & 12.5 & 2.5 & $122.6 \pm 0.9$ & 0.196 & $-9.3 \pm 0.8$ & $92.3 \pm 2.4$ \\
\hline 5\% GEII-LP/DOX & 10 & 5 & $123.4 \pm 0.5$ & 0.201 & $-8.9 \pm 0.2$ & $92.5 \pm 2.2$ \\
\hline I0\% GEI I-LP/DOX & 5 & 10 & $124.0 \pm 1 . \mid$ & 0.210 & $-10.3 \pm 0.4$ & $92.3 \pm 0.8$ \\
\hline I5\% GEI I-LP/DOX & 0 & 15 & $|24.2 \pm| .5$ & 0.206 & $-11.9 \pm 0.6$ & $92.0 \pm 1.1$ \\
\hline
\end{tabular}

Notes: Particle size and zeta potential of all the liposomes were determined by dynamic light scattering and each sample was diluted 20 -fold in distilled water ( $\mathrm{pH} 7.4$ ) before analysis. Data are presented as the mean \pm standard deviation $(n=3)$.

Abbreviations: DOX, doxorubicin; DSPE, I,2-distearoyl-sn-glycero-3-phosphoethanolamine; LP, liposome; PEG, polyethylene glycol; PDI, polydispersity index; EE, encapsulation efficiency. 

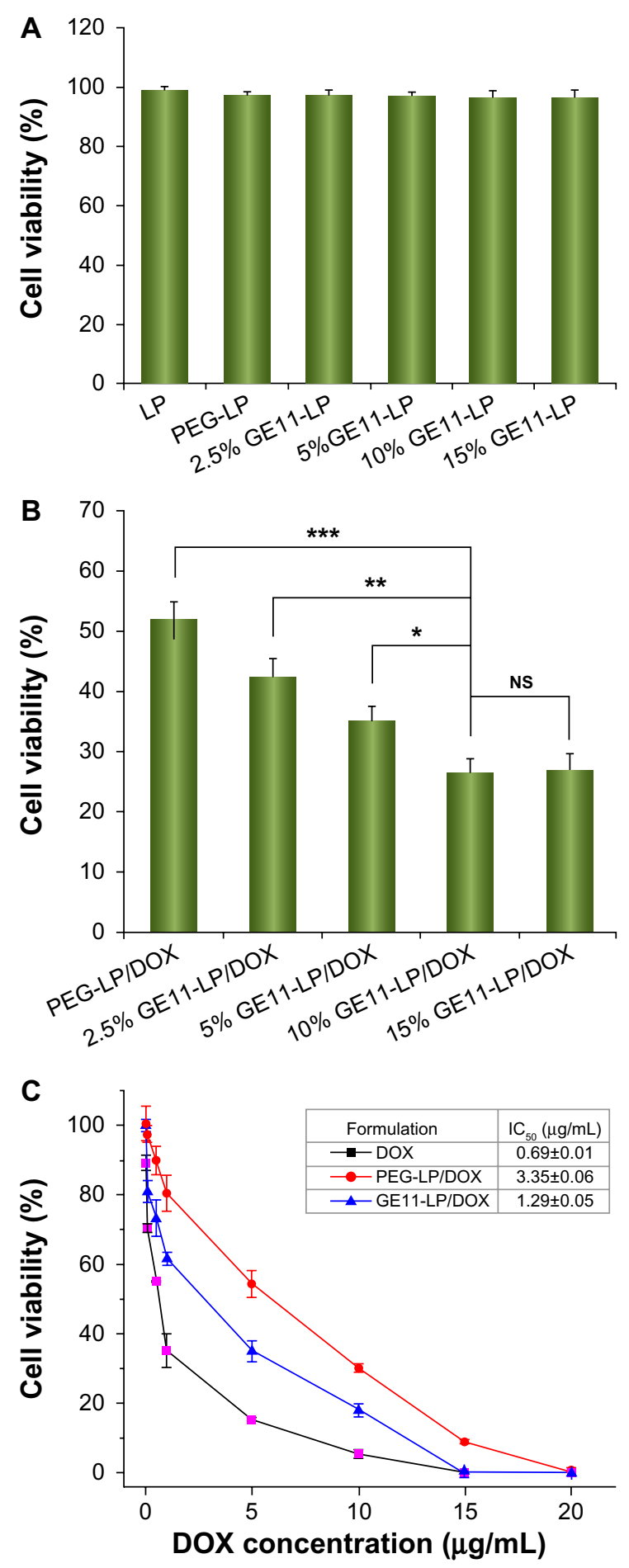

Figure 3 Cytotoxicity of the liposomal carriers without doxorubicin including plain liposomes, PEG-LP, and GEII-modified liposomes with different GEII densities (A) and cytotoxic effect of PEG-LP/DOX and GEII-LP/DOX with different GEII densities on A549 cells (B), and cell viabilities of A549 cells treated with doxorubicin, PEG-LP/DOX, or GEII-LP/DOX at different doxorubicin concentrations (C).

Notes: The doxorubicin concentration used was $7.5 \mu \mathrm{g} / \mathrm{mL}$ in the experiment for determining the cytotoxic effect of PEG-LP/DOX and GEII-LP/DOX with different GEII densities on $A 549$ cells. All data are shown as the mean \pm standard deviation $(\mathrm{n}=3) . * \mathrm{P}<0.05 ; * * \mathrm{P}<0.01$; *** $\mathrm{P}<0.00$ I.

Abbreviations: DOX, doxorubicin; PEG, polyethylene glycol; LP, liposomes; NS, not statistically significant. liposomal formulation was chosen for investigation in the studies followed.

The $\mathrm{IC}_{50}$ values for free doxorubicin, PEG-LP/DOX, and GE11-LP/DOX were determined by MTT assay and the results were shown in Figure 3C. At higher drug concentrations, both free doxorubicin and the liposomal formulations showed stronger cytotoxicity, indicated by decreasing cell viability. Although free doxorubicin was always associated with lower cell viability, its tumor killing activity would be impaired in vivo due to the lack of cell selectivity and shortterm retention in the body. It was noteworthy that the cell viability for GE11-LP/DOX was lower than that for PEG-LP/ DOX at all drug concentrations tested, further confirming that modification by GE11 indeed played a vital role in promoting the antitumor effect of the liposome. $\mathrm{The} \mathrm{IC}_{50}$ for GE11$\mathrm{LP} / \mathrm{DOX}$ was calculated to be $1.29 \mu \mathrm{g} / \mathrm{mL}$, which was 2.6 -fold lower than the $\mathrm{IC}_{50}$ for PEG-LP/DOX $(3.35 \mu \mathrm{g} / \mathrm{mL})$.

\section{Cellular uptake of the liposomes}

Confocal microscopy was used to investigate cellular uptake of the liposomes and the results were shown qualitatively by the fluorescent images in Figure 4. A549 cells treated with GE11-LP/DOX showed stronger fluorescence than PEGLP/DOX at both 1 hour and 2 hours, suggesting that GE11 could facilitate effective cellular uptake of the liposome. To verify further the role of GE11, A549 cells were preincubated with free GE11, which is believed to block specific binding of the GE11-modified liposome. As shown in Figure 4C and F, the uptake of GE11-LP/DOX was markedly inhibited to a degree similar to that achieved by PEG-LP/DOX, indicating that GE11 indeed possessed specific targeting ability for A549 cells. In addition, it was of note that the fluorescence of GE11-LP/DOX and PEG-LP/DOX became stronger with prolongation of the culture time, indicating that cellular uptake of the liposomes occurred in a timedependent manner.

Quantitative analysis of cellular uptake of the liposomes was performed by flow cytometry. As shown in Figure 5B, A549 cells consistently took up more GE11-LP/DOX and the mean fluorescence intensities were about 1.7-fold and 1.9-fold stronger than that for PEG-LP/DOX at 1 hour and 2 hours, respectively. Moreover, after treatment with free GE11, the mean fluorescence intensity for GE11-LP/DOX decreased significantly. These results agree fairly well with the observations made by fluorescence microscopy.

K562 tumor cells (which are EGFR-negative) were used to confirm further that improved cellular uptake of 


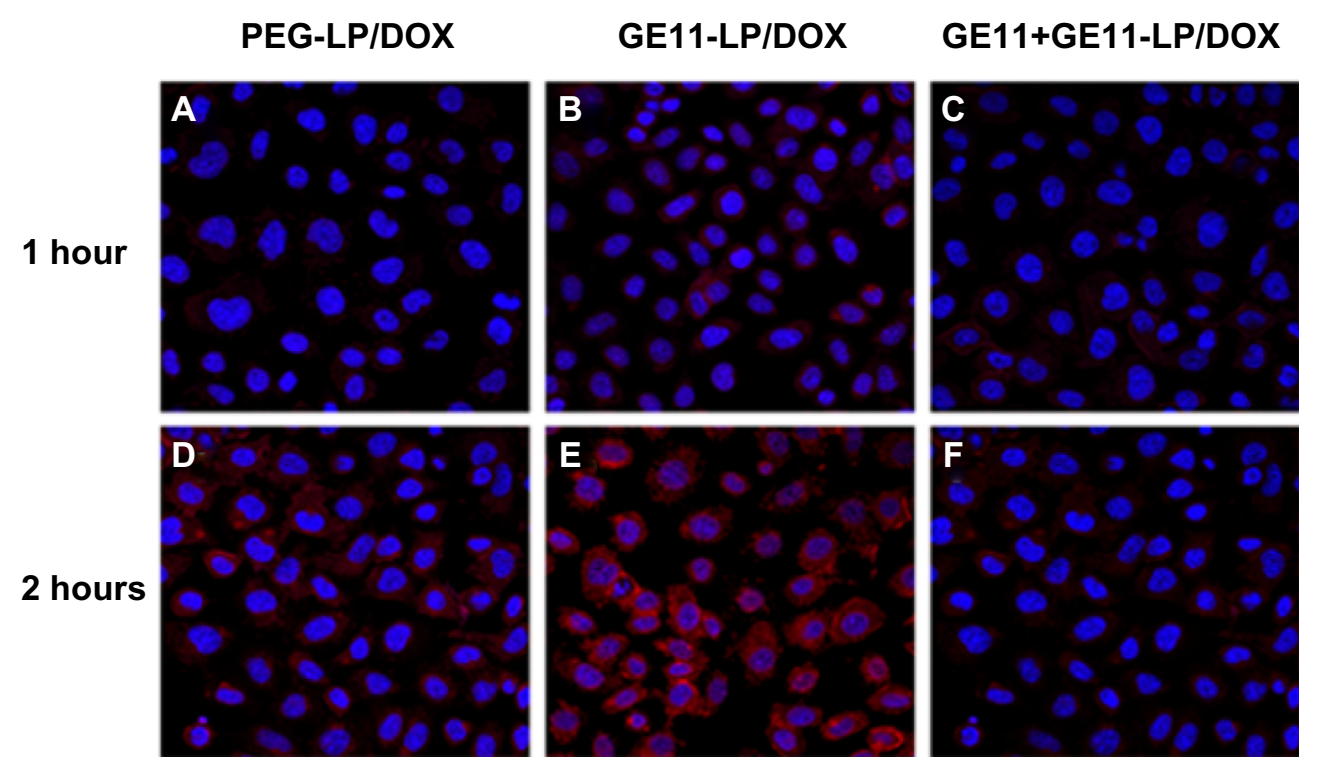

Figure 4 Confocal images of A549 cells treated with PEG-LP/DOX, GEII-LP/DOX, or GEII-LP/DOX preincubated with free GEII for I hour or 2 hours. Notes: The nucleus was stained with Hoechst 33342 and visualized as blue fluorescence, and PEG-LP/DOX and GEII-LP/DOX was visualized as red fluorescence. These images were taken at a magnification of $40 \times$.

Abbreviations: DOX, doxorubicin; PEG, polyethylene glycol; LP, liposomes.

the liposome was a result of specific EGFR-mediated endocytosis. As shown in Figure 5C, the mean fluorescence intensity for both liposomal formulations was nearly the same after incubation for one hour. In addition, no significant difference was noted in mean fluorescence intensity at 2 hours (data not shown). On the basis of these results, we can draw the conclusion that GE11 enables these liposomes to bind specifically to EGFR-positive A549 tumor cells and be taken up in an efficient manner.

\section{Cellular uptake mechanism of the liposomes \\ Effects of low temperature and ATP depletion on cellular uptake}

To elucidate whether the uptake of GE11-LP/DOX by A549 cells is an active energy-dependent or energy-independent process, the effect of low temperature and ATP depletion on cellular uptake was assessed. For comparison, cellular uptake of PEG-LP/DOX was also investigated under the same conditions. As shown in Figure 6A, low temperature markedly reduced cellular uptake of PEG-LP/ DOX and GE11-LP/DOX to $61.5 \%$ and $41.3 \%$ of the control value, respectively. In the ATP depletion experiment (Figure 6B), cellular uptake of PEG-LP/DOX and GE11-LP/ DOX was decreased to $68.9 \%$ and $57.0 \%$ of the control value after treatment with sodium azide and 2-deoxy-dglucose, both of which are agents causing depletion of the intracellular ATP pool. ${ }^{33,34}$ These results show that cellular uptake of GE11-LP/DOX and PEG-LP/DOX involves an active energy-dependent process.

\section{Effects of endocytosis inhibitors on cellular uptake}

Endocytosis can be broadly divided into phagocytosis and pinocytosis. Phagocytosis occurs only in some specific cells, including macrophages, neutrophils, and monocytes. Consequently, cellular uptake of nanocarriers could be ascribed to pinocytosis. In most cases, clathrin-mediated endocytosis, one type of pinocytosis, is the main route by which nanocarriers enter cells; however, this is not always the case. For instance, Oba et al have reported that caveolae-mediated endocytosis and not clathrin-mediated endocytosis is the primary route of cell entry for CRGD peptide-modified polymeric micelles. ${ }^{35}$ Hence it is worthwhile to gain an insight into which pathways are involved in endocytosis of liposomes and if there is a difference in this regard between GE11-modified liposomes and its non-modified counterpart. This study would help us to understand better the role of GE11 in the endocytosis process as well as in the intracellular fate of the liposome. Prior to the inhibition experiment, the cytotoxicity of the chosen concentration of inhibitors was evaluated. As shown in Figure 7A, cell viability was higher than 95\% at the concentration used for each inhibitor, indicating that the inhibitors were not toxic to A549 cells. Moreover, this result confirmed that the inhibition effect shown in Figure 7B was 


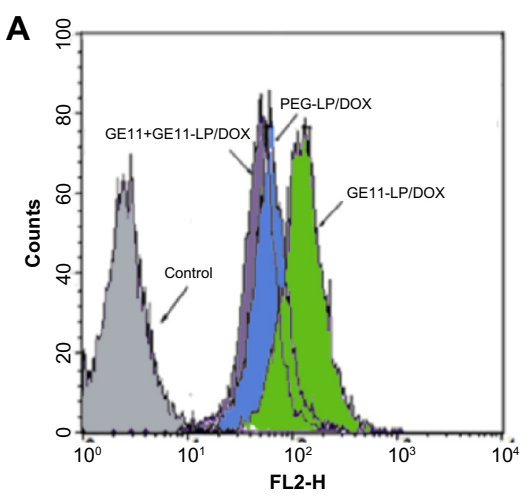

1 hour

B
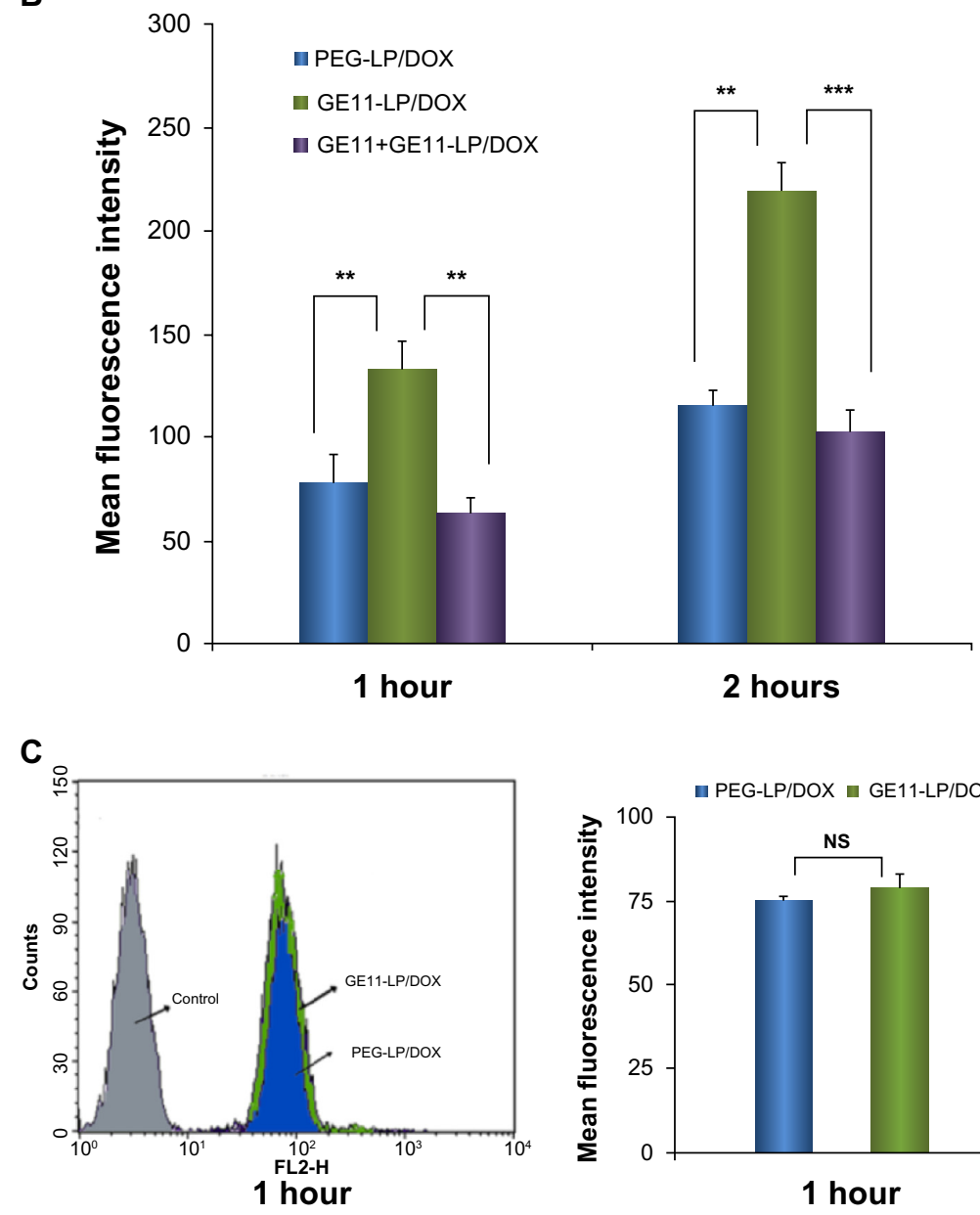

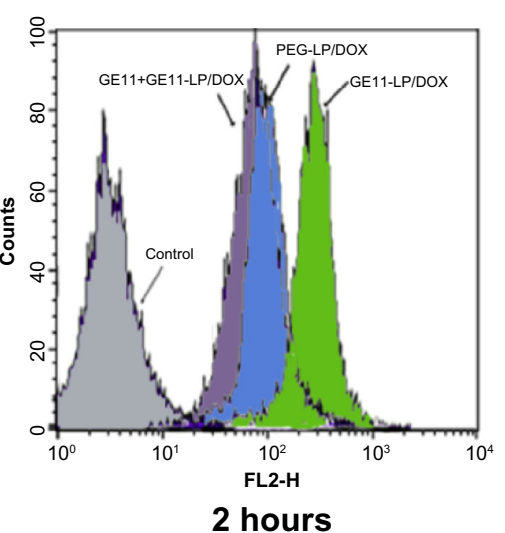

2 hours

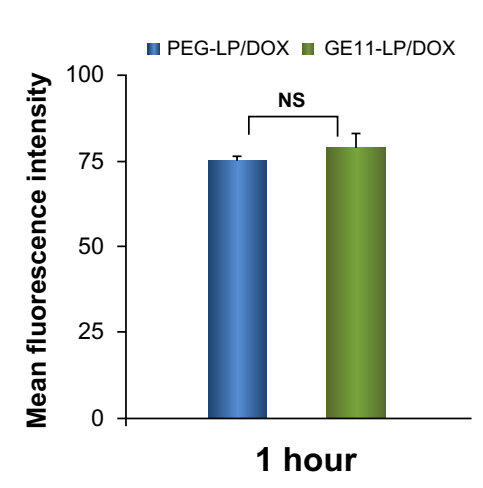

Figure 5 Flow cytometry studies of cellular uptake of liposomes showing histogram profiles and mean fluorescence intensities of doxorubicin in A549 cells treated with PEGLP/DOX, GEII-LP/DOX, and GEII-LP/DOX preincubated with free GEII (A and B) and the results of cellular uptake of PEG-LP/DOX and GEII-LP/DOX by K562 cells (C). Notes: Before determination by flow cytometry, A549 cells were rinsed three times in cold phosphate-buffered saline to remove the absorbed liposomes on the cell surface. In the competition experiments, free GEI I $(20 \mu \mathrm{g} / \mathrm{mL})$ was preincubated with A549 cells for 30 minutes, followed by continued incubation with GEI I-LP/DOX solution. The data are shown as the mean \pm standard deviation $(n=3)$. $* * P<0.01 ; * * * P<0.001$.

Abbreviations: DOX, doxorubicin; PEG, polyethylene glycol; LP, liposomes; NS, not statistically significant.

specific to the inhibitors rather than the cytotoxicity of the used endocytosis inhibitors.

Chlorpromazine was used to inhibit clathrin-mediated endocytosis via dissociation of the clathrin lattice. ${ }^{31,36}$ After treatment with chlorpromazine, the mean fluorescence intensities for PEG-LP/DOX and GE11-LP/DOX were decreased to $87.0 \%$ and $74.9 \%$ of control values, respectively, indicating that clathrin-mediated endocytosis was involved in cellular entry of PEG-LP/DOX and GE11-LP/DOX. Importantly, the inhibitory effect of chlorpromazine on 

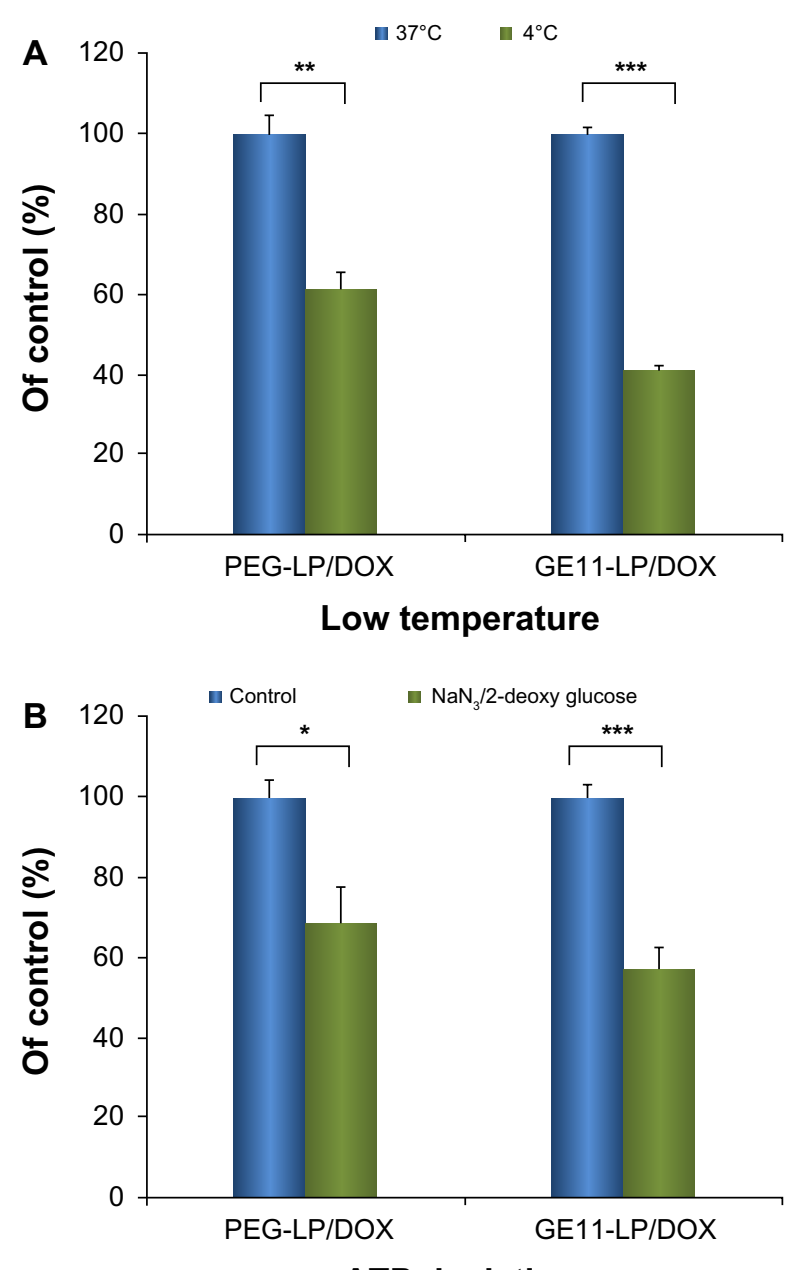

ATP depletion

Figure 6 Effects of low temperature (A) and ATP depletion (B) on cellular uptake of liposomes.

Notes: The low temperature experiment was performed by preincubating A549 cells at $4^{\circ} \mathrm{C}$ for 30 minutes. The ATP depletion experiment was performed by preincubating A549 cells with sodium azide $(10 \mathrm{mM})$ and 2-deoxy-d-glucose $(6.5 \mathrm{mM})$ at $37^{\circ} \mathrm{C}$ for one hour. The data are shown as the mean \pm standard deviation $(n=3)$. $* P<0.05$; ** $P<0.01$; *** $P<0.001$.

Abbreviations: DOX, doxorubicin; PEG, polyethylene glycol; LP, liposomes; NS, not statistically significant.

cellular uptake of GE11-LP/DOX was significantly stronger than that of PEG-LP/DOX $(P<0.01)$, suggesting that GE11 increased endocytosis of the liposome mainly via the clathrin-mediated pathway. Using colchicine, a specific inhibitor of macropinocytosis, ${ }^{34,37}$ the mean fluorescence intensities for PEG-LP/DOX and GE11-LP/DOX were reduced to $86.4 \%$ and $86.1 \%$ of the control value, respectively. Although these values were significantly lower than that of the control, the difference between PEG-LP/ DOX and GE11-LP/DOX was not significant, indicating that macropinocytosis participated in internalization of PEG-LP/ DOX and GE11-LP/DOX, but this endocytosis pathway was less dependent on GE11. Filipin was used as an inhibitor to specifically block caveolae-mediated endocytosis through

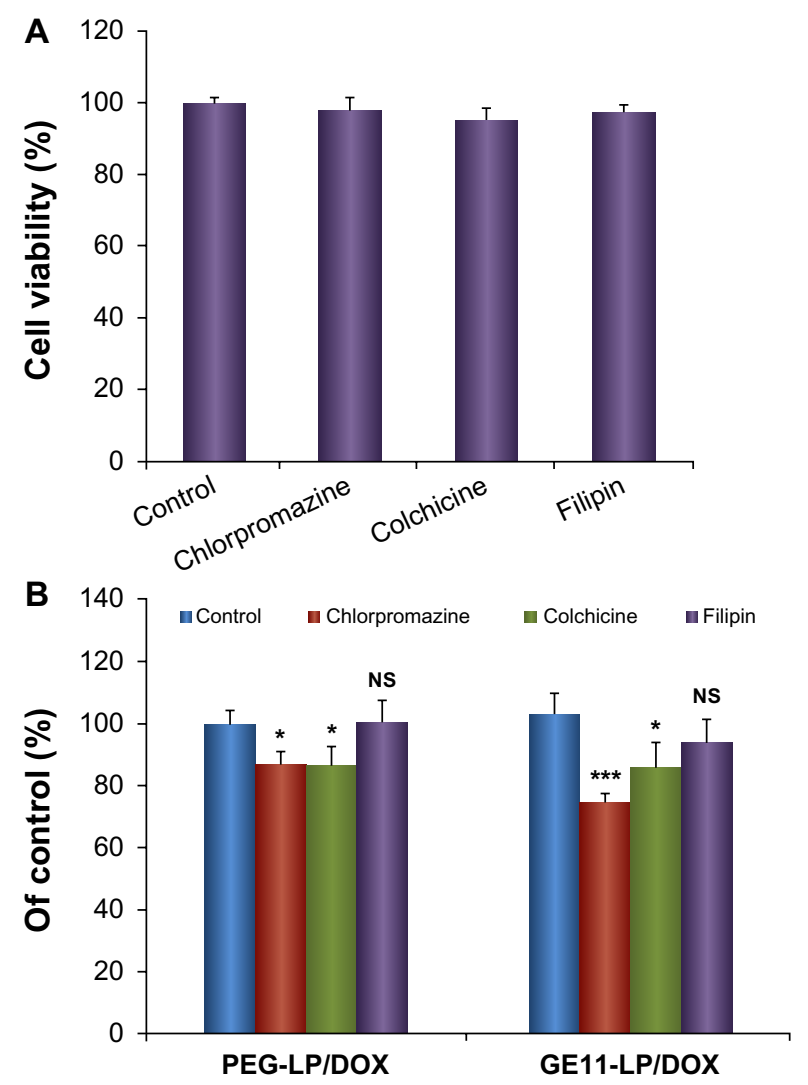

Figure 7 Experimental results of cellular uptake of liposomes treated with specific inhibitors. (A) Cytotoxicity of the chosen inhibitors against A549 cells. (B) Relative uptake percentages of PEG-LP/DOX and GEII-LP/DOX after treatment with different uptake inhibitors.

Notes: Cells in the presence of PEG-LP/DOX or GEII-LP/DOX but without treatment with inhibitors were used as controls and their mean fluorescence intensities were expressed as $100 \%$. The concentrations used of chlorpromazine, colchicine, and filipin were $10 \mu \mathrm{g} / \mathrm{mL}, 40 \mu \mathrm{g} / \mathrm{mL}$, and $4 \mu \mathrm{g} / \mathrm{mL}$, respectively. The data are shown as the mean \pm standard deviation $(n=3)$. $* p<0.05$; $* * * p<0.001$.

Abbreviations: DOX, doxorubicin; PEG, polyethylene glycol; LP, liposomes; NS, not statistically significant.

cholesterol depletion. ${ }^{33,38}$ It seemed that filipin did not inhibit cellular uptake of PEG-LP/DOX and only a small decrease in cellular uptake of GE11-LP/DOX was observed, confirming that the liposomes were not internalized via the caveolaemediated endocytosis pathway. Together, these findings suggest that multiple pathways are involved in endocytosis of the liposome and it is believed that GE11 exerts its function mainly via clathrin-mediated endocytosis.

\section{Subcellular localization of liposomes}

To verify further the endocytosis pathways via which the liposomes entered tumor cells, subcellular localization of PEG-LP/DOX and GE11-LP/DOX in A549 cells was investigated by confocal laser scanning microscopy. The nucleus and lysosomes were stained using Hoechst 33342 (blue) and Lyso tracker green (green), respectively. After one hour of incubation, both yellow fluorescence and red 
fluorescence were visible in the cytoplasm for PEG-LP/ DOX and GE11-LP/DOX (Figure 8A and H). The yellow fluorescence originated from the overlap of the red fluorescence of the liposome and the green fluorescence of the marked lysosomes. To our knowledge, nanocarriers internalized via clathrin-mediated endocytosis are eventually delivered into the acidic compartment of lysosomes. ${ }^{38,39}$ With regard to internalization via the macropinocytosis pathway, a nanocarrier can directly enter into the cytoplasm while bypassing lysosomes. ${ }^{40}$ The coexistence of yellow fluorescence and red fluorescence in the cytoplasm is consistent with the conclusion of the inhibition experiment. Further, more dots with yellow fluorescence were found in the cytoplasm for GE11-LP/DOX. This observation, from a different perspective, established that GE11 indeed assisted internalization of the liposome via the clathrin-mediated endocytosis pathway. With the passage of time, the intensity of either the yellow fluorescence or the red fluorescence was progressively strengthened (Figure 8L and P). Importantly, many purple dots were observed in the nucleus for GE11LP/DOX at 2 hours, which could be ascribed to overlap of the fluorescence of doxorubicin and that in the nucleus. In comparison, under otherwise the same conditions, less purple fluorescence was found in the nucleus for PEG-LP/
DOX. Based on this fact, it seems that GE11 is conducive to rapid cellular uptake and intracellular trafficking of the liposome.

\section{In vivo targeting study}

The targeting ability of GE11-PEG-LP in A549 tumorbearing nude mice was estimated using near-infrared fluorescence imaging. Prior to injection of GE11-LP through the tail vein, the liposome was labeled with near-infrared $\mathrm{Cy} 7$ dye. The near-infrared fluorescence signals of Cy7-labeled GE11-PEG-LP were monitored at scheduled time points and Cy7-labeled PEG-LP was used as the control. As shown in Figure 9A, both types of liposome were mainly concentrated in the organs, ie, the liver and spleen, in the first 2 hours. With increasing circulation time, the fluorescence intensity of PEG-LP and GE11-PEG-LP in these organs gradually decreased, while the fluorescence intensity in tumor tissue was steadily enhanced until accumulation of the liposomes in the tumor tissue reached a maximum 12 hours after injection. The increasing accumulation in tumor tissue over time could be ascribed to the enhanced permeability and retention effect. ${ }^{14,41}$ Moreover, it was interesting that the mean fluorescence intensity for GE11-PEG-LP in tumor tissue was always significantly stronger than that for PEG-

\section{PEG-LP/DOX}
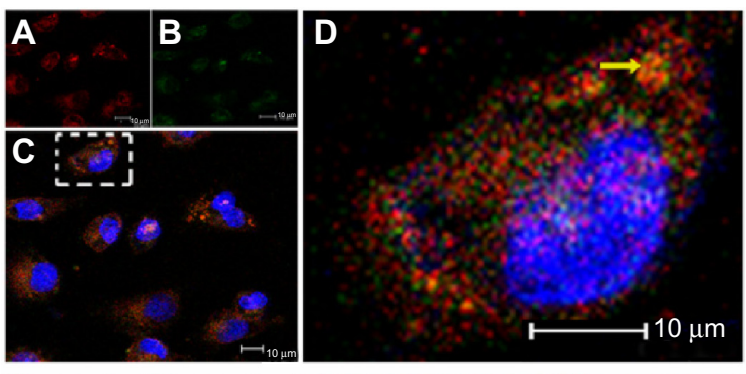

$2 \mathrm{~h}$
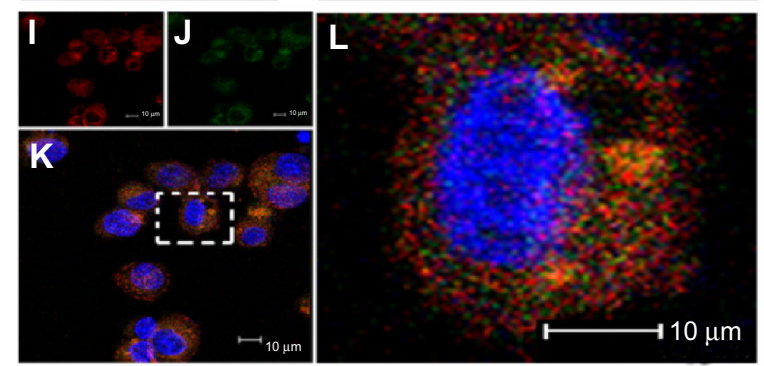

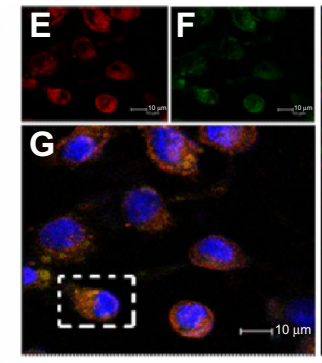

GE11-LP/DOX

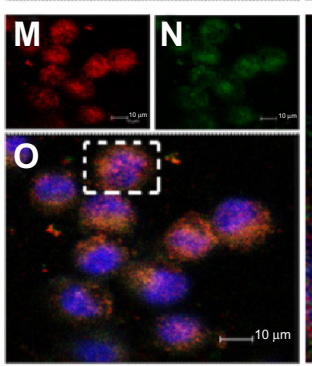

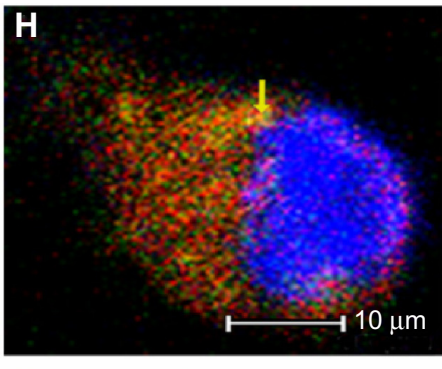

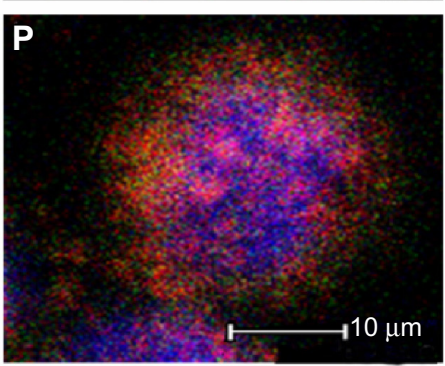

Figure 8 Confocal images of A549 cells after incubation with PEG-LP/DOX or GEII-LP/DOX for I hour or 2 hours. Liposomes were shown as red fluorescence (A, E, I and M), lysosomes were visualized as the green fluorescence after staining cells by Lyso tracker green (B, F, J and $\mathbf{N}$ ), and nucleus in each cell labeled with Hoechst 33342 stained a blue color. Overlapped images of the liposomes with lysosomes are shown in (C, G, K and $\mathbf{O}$ ) and magnified images of the white boxed area were displayed in (D, $\mathbf{H}, \mathbf{L}$ and $\mathbf{P})$.

Notes: A549 Cells were stained with Lyso tracker green $(80 \mu \mathrm{g} / \mathrm{mL})$ for 60 minutes and Hoechst $33342(10 \mu \mathrm{g} / \mathrm{mL})$ for $20 \mathrm{minutes}$, and the cells were then treated with $5 \%$ paraformaldehyde at room temperature for 15 minutes. The yellow fluorescence originated from the overlap of the red fluorescence of the liposomes with the green fluorescence of the marked lysosomes. The pink fluorescence originated from the overlap of the red fluorescence of DOX with blue fluorescence marked nucleus.

Abbreviations: DOX, doxorubicin; PEG, polyethylene glycol; LP, liposomes. 
A

$\begin{array}{llllll}\text { Bright field } & 2 \mathrm{~h} & 8 \mathrm{~h} & 12 \mathrm{~h} & 24 \mathrm{~h} & 36 \mathrm{~h}\end{array}$

PEG-LP

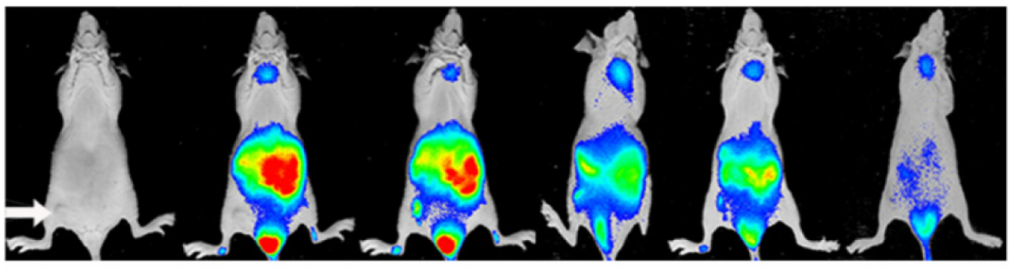

GE11-LP

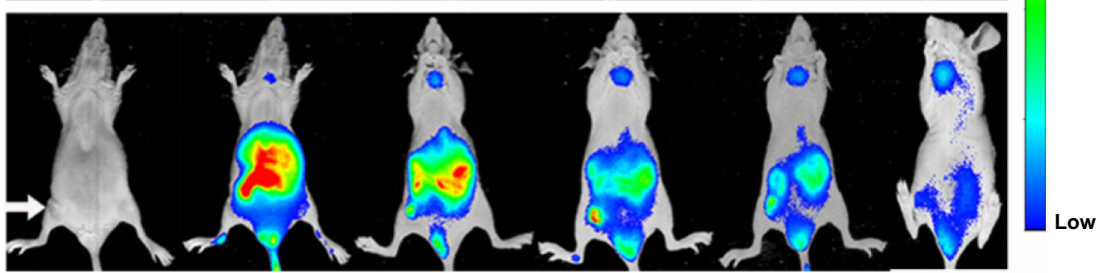

B

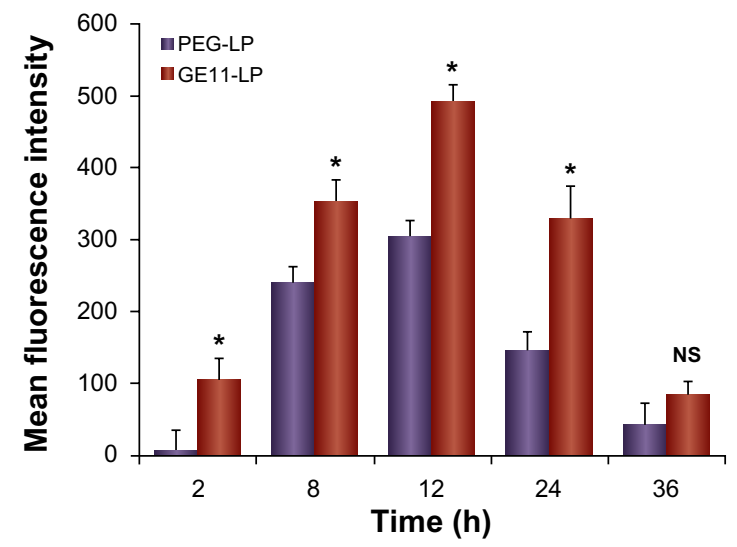

Figure 9 In vivo distribution of the liposomes in tumor-bearing nude mice after intravenous injection of Cy7-labeled liposomes. (A) Fluorescence images of Cy7-labeled liposomes in tumor-bearing nude mice, with tumor location pointed out with a white arrow. (B) Mean fluorescence intensity of Cy7-labeled liposomes in tumor sites at different time points.

Notes: Each experimental group contained three mice and the fluorescence intensity determined in the tumors is presented as the mean \pm standard deviation. $* P<0.05$. Abbreviations: LP, liposomes; PEG, polyethylene glycol; NS, not statistically significant; h, hours.

LP during the time period of 24 hours. It is widely accepted that accumulation of a nanocarrier in tumor tissue via the enhanced permeability and retention effect is primarily a size-dependent process, but if the nanocarrier reaching the tumor site cannot be taken up rapidly by tumor cells, the enhanced permeability and retention effect will be compromised due to weakened nanocarrier leakage into tumor tissues. ${ }^{42}$ As described in the aforementioned experiments, GE11 was capable of facilitating cellular uptake of the liposome. Therefore, it is reasonable to consider that GE11-mediated internalization accounts for the significant difference in mean fluorescence intensity between PEG-LP and GE11-PEG-LP in this in vivo study. Further, it seemed that GE11 was beneficial for slowing down elimination of the liposomes from the body, as demonstrated by the approximately 2.2-fold stronger mean fluorescence intensity for GE11-PEG-LP than that for PEG-LP at 24 hours. These results show that GE11-PEG-LP indeed has potential for active targeting to NSCLC overexpressing EGFR.

\section{Conclusion}

In the present study, a series of doxorubicin-loaded liposomes containing GE11 of varying density was successfully prepared, and modification by GE11 did not impact the characteristics of the liposomes, including size distribution, zeta potential, and entrapment efficiency. It was demonstrated that the cytotoxic effect of doxorubicin-loaded liposomes on A549 cells was closely related to GE11 density, and liposomes containing 10\% GE11 showed the highest tumor killing activity. GE11 was able to facilitate cellular uptake of the liposome via EGFR-mediated endocytosis and this process occurred in a time-dependent manner. Multiple endocytosis pathways appeared to be involved in entry of the liposome into the cell, and it was believed that GE11 assisted in internalization of the liposome mainly via clathrin-mediated endocytosis. An in vivo imaging experiment showed that modification using GE11 could increase accumulation and prolong retention of the liposome at the tumor site. This GE11-modified 
liposome may be a promising carrier for delivery of therapeutic drugs in NSCLC.

\section{Acknowledgments}

We are grateful for the financial support received from a project funded by the Priority Academic Program Development of Jiangsu Higher Education Institutions (PAPD), National Natural Science Foundation of China (81173004, 81202473), and Natural Science Foundation of Jiangsu Province (BK2012182).

\section{Disclosure}

The authors report no conflicts of interest in this work.

\section{References}

1. Parkin DM, Bray F, Ferlay J, Pisani P. Global Cancer Statistics, 2002. CA Cancer J Clin. 2005;55:74-108.

2. Rosell R, Felip E, Garcia-Campelo R, Balana C. The biology of nonsmall-cell lung cancer: identifying new targets for rational therapy. Lung Cancer. 2004;46:135-148.

3. Harper E, Dang WB, Lapidus RG, Garver RI. Enhanced efficacy of a novel controlled release paclitaxel formulation (PACLIMER delivery system) for local-regional therapy of lung cancer tumor nodules in mice. Clin Cancer Res. 1999;5:4242-4248.

4. Burris HA. Shortcomings of current therapies for non-small-cell lung cancer: unmet medical needs. Oncogene. 2009;28:S4-S13.

5. Wu NZ, Da D, Rudoll TL, Needham D, Whorton AR, Dewhirst MW. Increased microvascular permeability contributes to preferential accumulation of stealth liposomes in tumor-tissue. Cancer Res. 1993;53:3765-3770.

6. Xu X, Burgess DJ. Liposomes as carriers for controlled drug delivery. In: Wright J, Burgess DJ, editors. Long Acting Injections and Implants: New York, NY: CRC Press, Springer; 2012.

7. Yu K-F, Zhang W-Q, Luo L-M, et al. The antitumor activity of a doxorubicin loaded, iRGD-modified sterically-stabilized liposome on B16-F10 melanoma cells: in vitro and in vivo evaluation. Int $J$ Nanomedicine. 2013;8:2473-2485.

8. Alexis F, Pridgen E, Langer R, Farokhzad O. Nanoparticle technologies for cancer therapy. Drug Deliv. 2010;197:55-86.

9. Torchilin VP. Recent advances with liposomes as pharmaceutical carriers. Nat Rev Drug Discov. 2005;4:145-160.

10. Drulis-Kawa Z, Dorotkiewicz-Jach A. Liposomes as delivery systems for antibiotics. Int J Pharm. 2010;387:187-198.

11. Vemuri S, Rhodes CT. Preparation and characterization of liposomes as therapeutic delivery systems: a review. Pharm Acta Helv. 1995;70: $95-111$.

12. Immordino ML, Dosio F, Cattel L. Stealth liposomes: review of the basic science, rationale, and clinical applications, existing and potential. Int J Nanomedicine. 2006;1:297-315.

13. Byrne JD, Betancourt T, Brannon-Peppas L. Active targeting schemes for nanoparticle systems in cancer therapeutics. Adv Drug Deliv Rev. 2008;60:1615-1626.

14. Danhier F, Feron O, Preat V. To exploit the tumor microenvironment: Passive and active tumor targeting of nanocarriers for anti-cancer drug delivery. J Control Release. 2010;148:135-146.

15. Temming K, Schiffelers RM, Molema G, Kok RJ. RGD-based strategies for selective delivery of therapeutics and imaging agents to the tumour vasculature. Drug Resist Updat. 2005;8:381-402.

16. Benhabbour SR, Luft JC, Kim D, et al. In vitro and in vivo assessment of targeting lipid-based nanoparticles to the epidermal growth factorreceptor (EGFR) using a novel heptameric Z (EGFR) domain. J Control Release. 2012;158:63-71.
17. Danesi R, Pasqualetti G, Giovannetti E, et al. Pharmacogenomics in non-small-cell lung cancer chemotherapy. Adv Drug Deliv Rev. 2009;61:408-417.

18. Li ZH, Zhao RJ, Wu XH, et al. Identification and characterization of a novel peptide ligand of epidermal growth factor receptor for targeted delivery of therapeutics. FASEB J. 2005;19:1978-1985.

19. Master AM, Qi YZ, Oleinick NL, Sen Gupta A. EGFR-mediated intracellular delivery of Pc 4 nanoformulation for targeted photodynamic therapy of cancer: in vitro studies. Nanomedicine. 2012;8: 655-664.

20. Song S, Liu D, Peng J, et al. Peptide ligand-mediated liposome distribution and targeting to EGFR expressing tumor in vivo. Int $J$ Pharm. 2008;363:155-161.

21. Biswas S, Dodwadkar NS, Deshpande PP, Parab S, Torchilin VP. Surface functionalization of doxorubicin-loaded liposomes with octaarginine for enhanced anticancer activity. Eur J Pharm Biopharm. 2013;84:517-525.

22. Ducat E, Deprez J, Gillet A, et al. Nuclear delivery of a therapeutic peptide by long circulating $\mathrm{pH}$-sensitive liposomes: benefits over classical vesicles. Int J Pharm. 2011;420:319-332.

23. Iden DL, Allen TM. In vitro and in vivo comparison of immunoliposomes made by conventional coupling techniques with those made by a new post-insertion approach. Biochim Biophys Acta. 2001;1513: 207-216.

24. Li J, Li Y, Feng Z-Q, Chen X-G. Anti-tumor activity of a novel EGFR tyrosine kinase inhibitor against human NSCLC in vitro and in vivo. Cancer Lett. 2009;279:213-220.

25. Kim IY, Kang YS, Lee DS, et al. Antitumor activity of EGFR targeted pH-sensitive immunoliposomes encapsulating gemcitabine in A549 xenograft nude mice. J Control Release. 2009;140:55-60.

26. Yang T, Wang Y, Li Z, et al. Targeted delivery of a combination therapy consisting of combretastatin A4 and low-dose doxorubicin against tumor neovasculature. Nanomedicine. 2012;8:81-92.

27. Numico G, Castiglione F, Granetto C, et al. Single-agent pegylated liposomal doxorubicin (Caelix (R)) in chemotherapy pretreated nonsmall cell lung cancer patients: a pilot trial. Lung Cancer. 2002;35: $59-64$.

28. Jiang J, Yang S-J, Wang J-C, et al. Sequential treatment of drugresistant tumors with RGD-modified liposomes containing siRNA or doxorubicin. Eur J Pharm Biopharm. 2010;76:170-178.

29. Zhou Y, Daryl CD, Zou H, et al. Impact of single-chain fv antibody fragment affinity on nanoparticle targeting of epidermal growth factor receptor-expressing tumor cells. J Mol Biol. 2007;371:934-947.

30. Li YH, Wang J, Wientjes MG, Au JLS. Delivery of nanomedicines to extracellular and intracellular compartments of a solid tumor. Adv Drug Deliv Rev. 2012;64:29-39.

31. Sahay G, Alakhova DY, Kabanov AV. Endocytosis of nanomedicines. $J$ Control Release. 2010;145:182-195.

32. Kuai R, Yuan W, Qin Y, et al. Efficient delivery of payload into tumor cells in a controlled manner by tat and thiolytic cleavable PEG comodified liposomes. Mol Pharm. 2010;7:1816-1826.

33. Benfer M, Kissel T. Cellular uptake mechanism and knockdown activity of siRNA-loaded biodegradable DEAPA-PVA-g-PLGA nanoparticles. Eur J Pharm Biopharm. 2012;80:247-256.

34. Zhu SJ, Hong MH, Zhang LH, Tang GT, Jiang YY, Pei YY. PEGylated PAMAM dendrimer-doxorubicin conjugates: in vitro evaluation and in vivo tumor accumulation. Pharm Res. 2010;27: 161-174.

35. Oba M, Aoyagi K, Miyata K, et al. Polyplex micelles with cyclic RGD peptide ligands and disulfide cross-links directing to the enhanced transfection via controlled intracellular trafficking. Mol Pharm. 2008;5: 1080-1092.

36. Perumal OP, Inapagolla R, Kannan S, Kannan RM. The effect of surface functionality on cellular trafficking of dendrimers. Biomaterials. 2008;29:3469-3476.

37. Mercer J, Helenius A. Virus entry by macropinocytosis. Nat Cell Biol. $2009 ; 11: 510-520$ 
38. Peng SF, Tseng MT, Ho YC, Wei MC, Liao ZX, Sung HW. Mechanisms of cellular uptake and intracellular trafficking with chitosan/DNA/ poly(gamma-glutamic acid) complexes as a gene delivery vector. Biomaterials. 2011;32:239-248.

39. Rappoport JZ. Focusing on clathrin-mediated endocytosis. Biochem J. 2008;412:415-423.

40. Luhmann T, Rimann M, Bitterman AG, Hall H. Cellular uptake and intracellular pathways of PLL-g-PEG-DNA nanoparticles. Bioconjug Chem. 2008;19:1907-1916.
41. Jiang XY, Sha XY, Xin HL, et al. Self-aggregated pegylated poly (trimethylene carbonate) nanoparticles decorated with c(RGDyK) peptide for targeted paclitaxel delivery to integrin-rich tumors. Biomaterials. 2011;32:9457-9469.

42. Gao Z, Zhang L, Sun Y. Nanotechnology applied to overcome tumor drug resistance. J Control Release. 2012;162:45-55.
International Journal of Nanomedicine

\section{Publish your work in this journal}

The International Journal of Nanomedicine is an international, peerreviewed journal focusing on the application of nanotechnology in diagnostics, therapeutics, and drug delivery systems throughout the biomedical field. This journal is indexed on PubMed Central, MedLine, CAS, SciSearch $®$, Current Contents ${ } /$ Clinical Medicine,

\section{Dovepress}

Journal Citation Reports/Science Edition, EMBase, Scopus and the Elsevier Bibliographic databases. The manuscript management system is completely online and includes a very quick and fair peer-review system, which is all easy to use. Visit http://www.dovepress.com/ testimonials.php to read real quotes from published authors.

Submit your manuscript here: http://www.dovepress.com/international-journal-of-nanomedicine-journal 